\title{
Elaborated Mathematical Model for Hydrogen-Hydrogen-Oxygen Energy Storage Cell
}

\author{
HESHAM M. ENSHASY ${ }^{1}$, QASEM ABU AL-HAIJA ${ }^{2}$, HASAN AL-AMRI ${ }^{1}$, \\ MOHAMED AL-NASHRI ${ }^{1}$, SULTAN AL-MUHAISEN ${ }^{1}$, MASHHOUR AL-TARAYRAH ${ }^{1}$ \\ ${ }^{1}$ Department of Electrical Engineering, \\ King Faisal University \\ Al-Ahsa, Saudi Arabia \\ ${ }^{2}$ Computer and Information Systems Engineering Department, \\ Tennessee State University \\ Nashville, TN, USA
}

\begin{abstract}
Hydrogen is now considered one of the most promising fuel of the future. It will be used in various applications, e.g. generating and storing electricity, fuel for automobiles and Jet Planes, hydrogen powered industries, and for all our domestic energy requirements. The challenges of efficiently generating and storing the Hydrogen gas is the playing field of many researchers around the globe. In this paper we studied three different designs of the generation cell where an elaborated design models for these three designs are put forth. The three designs were modeled into three electric circuits to calculate the plate's parameters such as resistance, inductance and capacitance. A theoretical comparison based on these three parameters, has applied to determine the optimum design. A spiral plate design shows the highest HHO gases generation. The simulation data showed also, that minimizing the voltage at least to be $1.23 \mathrm{~V}$, will increase the effective current hence improving the efficiency. On the other hand, shaping the input signal to the energy generation system, will lead to stabilizing the temperature and reduce the power loses.
\end{abstract}

Keywords:- Clean Energy Storage, Brown Gas, Electrolysis, Energy, HHO Cells, Photovoltaic.

Received: November 12, 2019 Revised: April 30, 2020. Accepted: May 15, 2020. Published: May 29, 2020

\section{Introduction}

The world energy consumption shows significant increase for the last three decades which causes rapid increase in earth pollution and pushed up the global warming to be a serious threat to mother earth. Reasearchers worldwide working hard in reducing the pollution associated with power generation and storing. There should be efficient solutions that will reduce pollution to maintain safe environment for us and generations to come. Pollution and global warming are a major problem out of many other problems that need immediate yet green solutions [1]. Renewable energy which is most of the time clean and relatively non-harmful source of energy is a possible contemporary solution. Energy storage from renewable sources is a major part of this technology. In most cases large scale battery storage facilities associated with initial high establishing cost and frequent maintenance needs considering the battery lifetime. A side from cost, storing and using energy on demand via batteries create great amount of pollution in the form of waste of fabricating batteries and the wasted batteries itself after usage. Batteries contains hazard chemicals such as acids, Lead, lithium and other substances. For instance, Lead acid batteries consist of positive electrodes of lead dioxide and a negative electrodes of sponge lead, immersed in an aqueous sulfuric acid electrolyte. Indeed, these chemicals are not environment friendly.

Pollution problem from batteries can be decreased by recycling -which is not cost-effectiveor eliminating battery use by introducing new innovative green energy storage devices into the power system network [2]. Alternatively, HydrogenHydrogen Oxygen (HHO) cells are newly developed innovative solution to store energy with no harm effects for any of the beings on earth. HHO generation cells are introduced to be a green alternative energy storage source because of its advantages, which have overcome the environment pollution and global worming issues. HHO generation cell is environmentally friendly because the hydrogen burns completely without creating pollutants, toxic fumes, or public nuisance. The HHO cells itself mainly in its simplest form stainless steel material that uses water (Saltwater increase the reaction more than the regular water) as an in product. The waste of the system is pure distilled 
water that can be used as drinking water after mixed with tap water. The output of HHO system is oxygen and hydrogen gases, where hydrogen gas can be stored and used efficiently as power source. Number of factors are influencing the operating mechanism of the HHO generator and the quantity of the gas produced. Current density, concentration of the electrolyte, temperature, the frequency of the supplied voltage, and distance between the electrodes are some of these factors. One method of determining the efficiency of electrolysis process is the calculation of Milliliter per Minute per Watt (MMW) value, determining the ratio of the quantity of the produced gas to the consumed electricity [3].

The use of Hydrogen gas as supplementary source of power is not a new idea. It has been studied by several researches and experiments to enhance, reduce and eliminate certain features of certain systems. For instance, early in 1920s, R.A. Erren [4] designed practical hydrogen-fueled engine and converted over 1,000 engines to work in hydrogenfuel. Also, since World War I, submarines were using hydrogen as a fuel and the major benefit comes from that was pure drinking water generation as a system waste. Moreover, Stebar and Parks [7], two General Motors engineers, have investigated the hydrogensupplemented fuel effects on emission control with lean operation. The investigation results have demonstrated that a small addition of hydrogen to the fuel, very low oxides of nitrogen (NOx) and $\mathrm{CO}$ emissions were achieved for hydrogen-isooctane mixtures leaner than equivalence ratio of 0.55 and there was significant thermal efficiency improvement yields from the extension further than isooctane lean limit operation.
Similarly, R. Zweig [8] has converted an engine of pickup truck to be powered by compressed hydrogen known as the American Hydrogen. Nowadays one of the main consumers of non-renewable energy sources are the internal combustion engines, which are characterized by relatively low efficiency. Lately more and more widely used is the oxyhydrogen known as Brown's gas.t is used as a supplement to the air mixture of an internal combustion engine. This is achieved a reduction of fuel consumption [5 and 6].

In this paper three different designs of the generation cell of the brown gas will be studied where elaborated models for these three designs will be put forth. Equivalent circuits of the three designs will be introduced. The plate's parameters such as resistance, inductance and capacitance will be calculated. A theoretical comparison based on these three parameters, will be applied to determine the optimum design. A spiral plate design shows the highest HHO gases generation. The simulation data showed also, that minimizing the voltage at least to be $1.23 \mathrm{~V}$, will increase the effective current, hence improving the efficiency. On the other hand, shaping the input signal to the energy generation system, will lead to stabilizing the temperature and reduce the power loses

\section{HHO Generator Models}

The HHO generator can be designed in different configurations. It can be designed as parallel plates Figure 1a, cylindrical tubes Figure 1b, or spiral plates cells Figure 1c. In this paper, will look at the equations that control the input and output power and simulate the HHO output of these designs. (a)

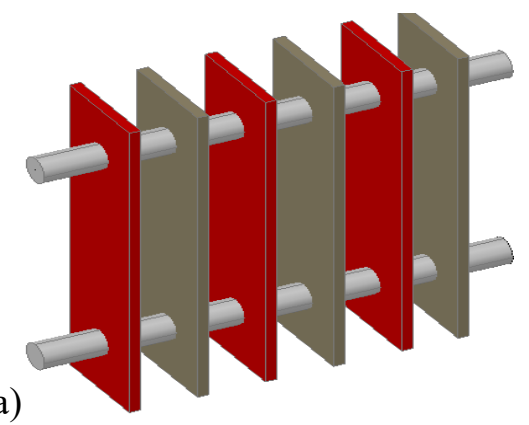

(b)

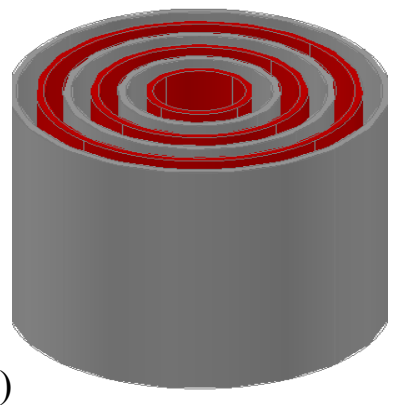

(c)

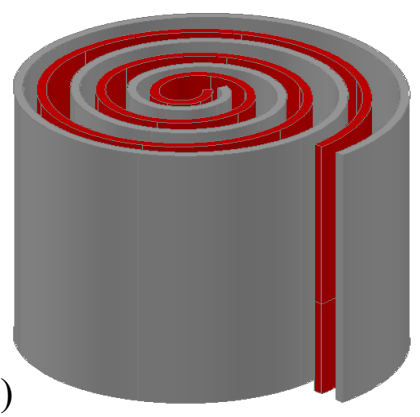

Fig.1. Three assorted designs for HHO Cell (a) Parallel Plates (b) Cylindrical tubes (c) Spiral Plates

\subsection{Design Equations of Parallel Plates Water Cell}

The parallel plate design can be simulated as a capacitor in parallel with resister. An equivalent circuit of the parallel plates is illustrated in figure 2. If we assume that the parallel plates area is
$A=0.01 \mathrm{~m}^{2}$ (each plate multiply with number of plates to get total area), and the distance between each two adjacent plates is $d=0.01 \mathrm{~m}$, and applied power on this area is $\mathrm{S}=0.25 \mathrm{VA}$. 

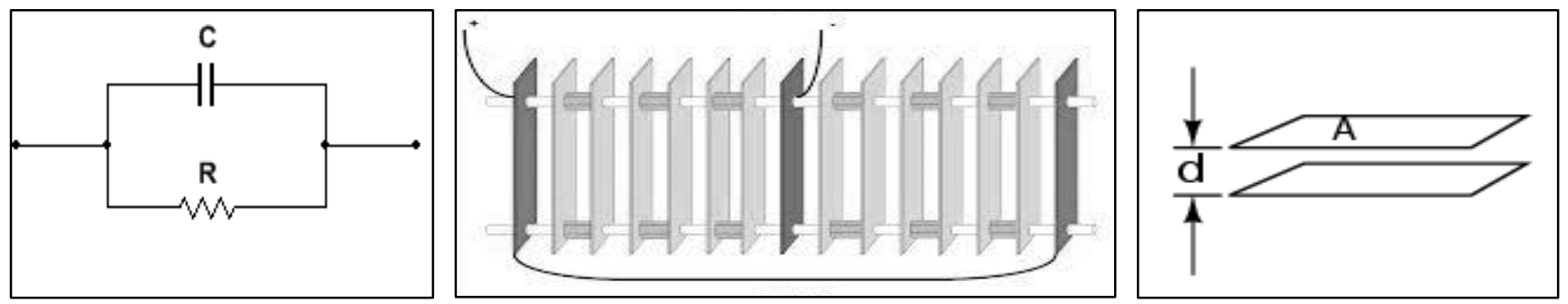

Fig. 2: Simulation of Parallel Plate (a) Equivalent circuit (b) Parallel Plates Design, (c) Parallel Plate (Capacitor).

To avoid reversing direction of current and to increase the amount of releasing $\mathrm{HHO}$, the voltage apply to this system has to be positive, therefore it is given by: $V=v(1+\cos (\omega t))$. Where, $v$ (constant) is the mean voltage of the alternate voltage $\mathrm{V}, \omega=$ $2 \pi f$; and the frequency assumed to be $f=40 \mathrm{khz}$.

\subsubsection{Parallel Plates Capacitance:}

The capacitance of any capacitor is given by: $C=\varepsilon A / d$ Where: $\mathrm{C}$ : Capacitance in Farads, $\varepsilon$ : Permittivity of dielectric (absolute, not relative), A: Area of plate overlap in square meter $\left(\mathrm{m}^{2}\right)$, and $\mathrm{d}$ : Distance between plates in meter $(\mathrm{m})$. The permittivity of dielectric is given by [9]: $\varepsilon=\varepsilon_{0} \varepsilon_{r}$, where: $\varepsilon_{0}$ : Permittivity of free space which is constant $\varepsilon_{0}=8.8562 \times \frac{10^{-12} F}{m}, \quad \varepsilon_{r}:$ Dielectric constant of material between the plates which is water in this design $\left(\varepsilon_{r}=80\right)$ for distilled water [10]. The capacitance of this system is:

$$
\begin{gathered}
C=\frac{\varepsilon A}{d}=\frac{\varepsilon_{0} \varepsilon_{r} A}{d}= \\
\frac{\left(8.8562 \times 10^{-12}\right)(80)(0.01)}{0.01}=708.50 p F
\end{gathered}
$$

The reactance $\left(X_{c}\right)$ of the system because of this capacitor is

$$
\begin{gathered}
X_{C}=\frac{1}{j \omega C}=\frac{1}{j\left(80 \pi \times 10^{3}\right)\left(708.5 \times 10^{-12}\right)} \\
=-j 5.6159 \mathrm{k} \Omega
\end{gathered}
$$

\subsubsection{Parallel Plate's Resistance:}

The resistance of this design is given by: $R=\rho(d / A)$ Where: $\rho$ : The resistance for each meter which equal in this design $\rho$ (distilled water) $=$ $5 \mathrm{k} \Omega . \mathrm{m}$, A: Area of plate overlap in square meter $\left(\mathrm{m}^{2}\right), A=0.01 \mathrm{~m}^{2}$, and d: Distance between plates in meter $(\mathrm{m}), d=0.01 \mathrm{~m}$. The resistor of this system is:

$$
R=\rho \frac{d}{A}=5 k \Omega \cdot m \frac{0.01 m}{0.01 m^{2}}=5 k \Omega
$$

\subsubsection{Parallel Plate's Impedance:}

The impedance of this design is $Z_{\text {cell }}$ and since the resister is parallel to the capacitor, impedance will be:

$$
\begin{gathered}
Z_{\text {cell }}=\frac{X_{c} R}{X_{c}+R}=\frac{\left(-j 5.6159 \times 10^{3}\right)\left(5 \times 10^{3}\right)}{-j 5.6159 \times 10^{3}+5 \times 10^{3}} \\
=2.789 k-j 2.4832 k \Omega
\end{gathered}
$$

The magnitude of the impedance is: $Z=\left|Z_{\text {cell }}\right|=$ $|2.789 k-j 2.4832 k|=3.734 k \Omega$. The equivalent circuit for these parallel plates is given in figure 3 .

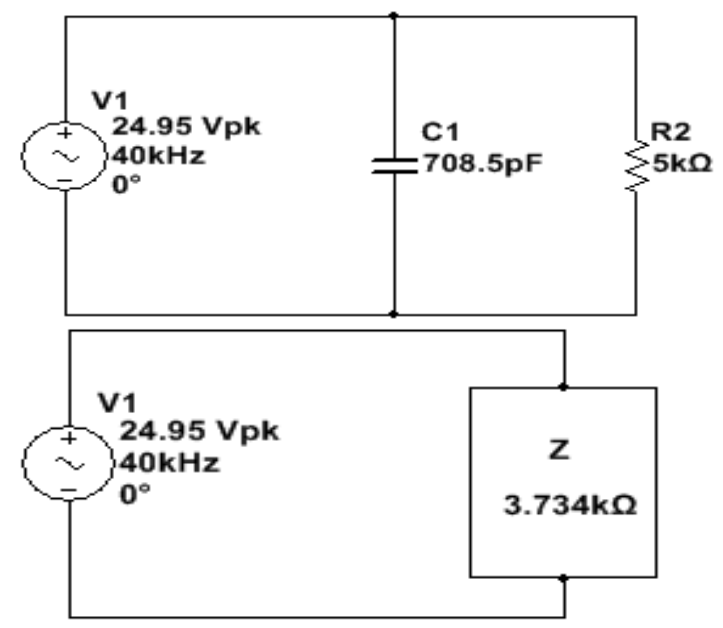

Fig. 3. Parallel plates equivalent electric circuit.

\subsubsection{Parallel Plate's Mean Voltage:}

To calculate the mean current $i$, the mean voltage $v$ needs to be calculated. Therefore: The alternate voltage $\mathrm{V}$ equation is: $\mathrm{V}=\mathrm{v}(1+\cos (\omega \mathrm{t}))$. It is known that the apparent power can be obtained by this equation:

$$
S=\frac{V^{2}}{Z} \Rightarrow S_{a v r}=\frac{\left(V^{2}\right)_{a v r}}{Z}
$$

Where: $S$ : Apparent power - Unit VA (depends on time) and $S_{a v r}$ : Average apparent power (constant) which is $0.25 \mathrm{VA}$. Apply the average on alternate voltage $\mathrm{V}$ :

$$
\begin{aligned}
& \left(V^{2}\right)_{a v r}=\left(v^{2}(1+\cos (\omega t))^{2}\right)_{a v r} \\
= & v^{2}\left(1+2 \cos (\omega t)+\cos (\omega t)^{2}\right)_{a v r}
\end{aligned}
$$




$$
\begin{gathered}
V_{a v r}^{2}=v^{2}\left(1+\left(\frac{2+(-2)}{2}\right)+\left(\frac{1+0}{2}\right)\right)=1.5 v^{2} \\
S_{a v r}=\frac{V^{2}{ }_{a v r}}{Z}=\frac{v^{2} 1.5}{Z} \quad \Rightarrow \quad v=\sqrt{\frac{S_{a v r} Z}{1.5}} \\
=\sqrt{\frac{(0.25)(3.734 k)}{1.5}}=24.947 \mathrm{~V}
\end{gathered}
$$

The mean voltage $v=24.95 \mathrm{~V}$. The alternate voltage V is: $V=24.95\left(1+\cos \left(80 \pi t \times 10^{3}\right)\right) \boldsymbol{V}$

\subsubsection{The Effective Current:}

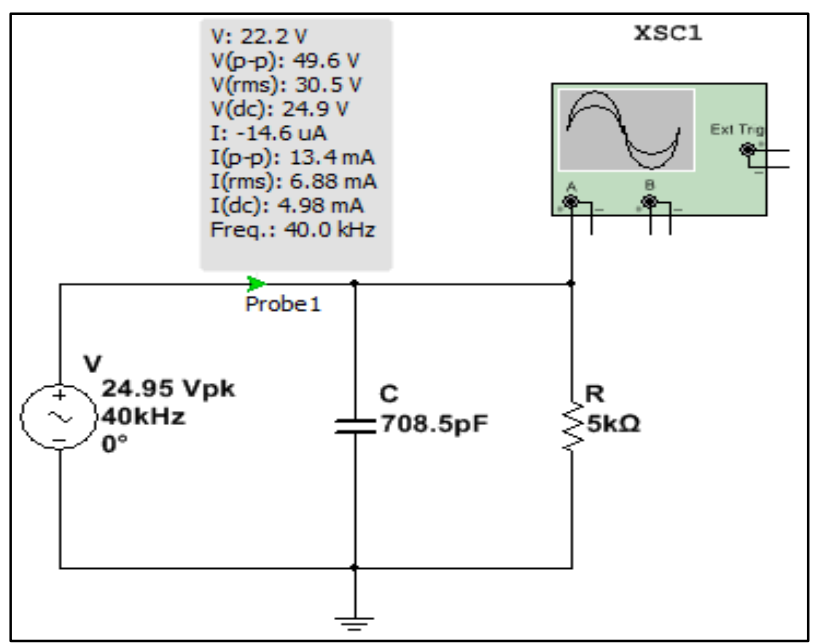

The effective current is the current that passes through the water to separate it to HHO. The alternate current is given by:

$$
\begin{aligned}
I & =\frac{V}{Z}=\frac{24.95\left(1+\cos \left(80 \pi t \times 10^{3}\right)\right)}{3.734 k \Omega} \\
& =6.7\left(1+\cos \left(80 \pi t \times 10^{3}\right)\right) m \boldsymbol{A}, \\
& =>\text { Mean current } \boldsymbol{i}=\mathbf{6 . 7} \mathbf{m A}
\end{aligned}
$$

The equivalent circuit of parallel plates cell along with its simulation results of using Multisim is given in fig.4.

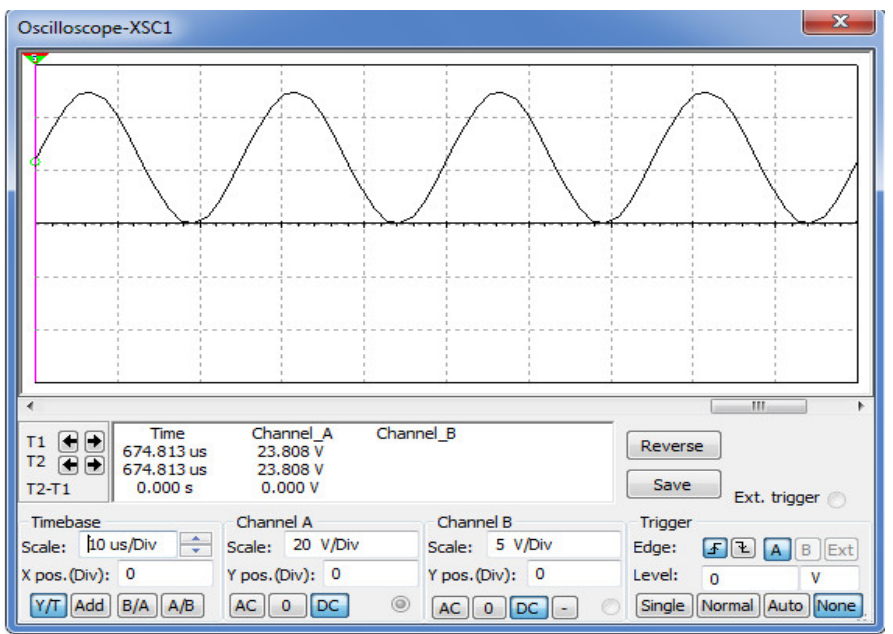

Fig. 4. (a) Equivalent circuit of parallel plates using MULTISIM, (b) Simulation result of parallel plate using MULTISIM.

\subsubsection{Released Volume Of HHO:}

To calculate the volume and energy released by HHO gases, the current needs to be converted to moles since it is known that each mole of electrons passes from cathode to anode will release $1 / 2 \mathrm{H}_{2}$ and $1 / 4 \mathrm{O}_{2}$.

$$
\text { Amp }=\frac{\text { Coulomp }}{\text { Second }} \Rightarrow A m p=\frac{6.28 \times 10^{18} \text { electrons }}{\text { Second }}
$$

Now, convert amperes to electrons:

$$
\begin{gathered}
i=\left(6.7 \times 10^{-3} A\right)=6.7 \times 10^{-3}\left(6.28 \times 10^{18} e^{-} / s\right) \\
=42.076 \times 10^{15} e^{-} / s .
\end{gathered}
$$

Then, convert electrons to moles:

$$
\begin{gathered}
i=\frac{42.076 \times 10^{15 e^{-} / \mathrm{s}}}{6.022 \times 10^{23 e^{-}} / \mathrm{mol}}=69.87 \times 10^{-9} \mathrm{~mol} / \mathrm{s} \\
1 \text { mol of electrons } \stackrel{\text { yields }}{\longrightarrow} \frac{1}{2} H_{2}+\frac{1}{4} \mathrm{O}_{2} \\
=\frac{1}{4}\left(2 \mathrm{H}_{2}+\mathrm{O}_{2}\right)
\end{gathered}
$$$$
i \stackrel{\text { yields }}{\longrightarrow} 17.47 \times 10^{-9} \frac{\mathrm{mol}}{\mathrm{s}}\left(2 \mathrm{H}_{2}+\mathrm{O}_{2}\right)
$$

The volume of $\mathrm{H}_{2}$ and $\mathrm{O}_{2}$ are $24.64 \mathrm{~L}$ for one mole of them, as derived in the chemical section.

$$
\begin{gathered}
1 \mathrm{~mol} \text { of }\left(2 \mathrm{H}_{2}+\mathrm{O}_{2}\right)=24.64 \mathrm{~L} / \mathrm{mol} \\
i \stackrel{\text { yields }}{\longrightarrow}\left(17.47 \times 10^{-9} \frac{\mathrm{mol}}{\mathrm{s}}\left(2 \mathrm{H}_{2}+\mathrm{O}_{2}\right)\right)(24.64 \mathrm{~L} / \mathrm{mol}) \\
=429.16 \times 10^{-9} \mathrm{~L} / \mathrm{s} \quad\left(2 \mathrm{H}_{2}+\mathrm{O}_{2}\right)
\end{gathered}
$$

\subsubsection{Energy Released by HНО:}

$2 \mathrm{H}_{2}(\mathrm{~g})+\mathrm{O}_{2}(\mathrm{~g}) \rightarrow 2 \mathrm{H}_{2} \mathrm{O}(\mathrm{l})+572 \mathrm{~kJ}(286 \mathrm{~kJ} /$ mole $)$ and 1 mole $\left(2 \mathrm{H}_{2}+\mathrm{O}_{2}\right) \rightarrow 572 \mathrm{~kJ} / \mathrm{mole}$

$$
\begin{aligned}
& 17.47 \times 10^{-9} \mathrm{~mole}_{\mathrm{s}}\left(2 \mathrm{H}_{2}+\mathrm{O}_{2}\right) \\
\rightarrow & \frac{572 \mathrm{~kJ}}{\mathrm{~mole}} 17.47 \times 10^{-9} \mathrm{~mole} / \mathrm{s}=10 \mathrm{~mW}
\end{aligned}
$$




\subsection{Design Equations of Cylindrical Tubes Cell}

The cylindrical tubes cell design can also be simulated as a capacitor in parallel with resister. Assume that the area of cylinders is $A=0.01 \mathrm{~m}^{2}$ and the distance between them is $d=0.01 \mathrm{~m}$, the height of the cylindrical is $h=0.01 \mathrm{~m}$, the applied power on this design is $\mathrm{S}=0.25 \mathrm{VA}$ and the frequency will be also $f=40 \mathrm{khz}$ as before.

\subsubsection{Cylindrical tubes capacitance:}

The capacitance of this design can be given by [11]: $C=h\left(2 \pi \varepsilon / \ln \left(\frac{b}{a}\right)\right)$, where: C: Capacitance in Farads, $\varepsilon$ : Permittivity of dielectric, $a$ : Inner radii in meter $(\mathrm{m}), b$ : Outer radii in meter $(\mathrm{m}), h$ : The height of the cylindrical in meter $(\mathrm{m}), h=0.01 \mathrm{~m}$.

\subsubsection{The Capacitance of the System:}

To find $a$ and $b$ the total area must equal the previous design: $b=a+d=a+0.01 m$

Cylindrical plates area $=$ square plates area

$$
\begin{aligned}
& \Rightarrow 2 \pi h(a+b)=2 A=>2 \pi h(2 a+0.01 m)=2 A \\
& a=\frac{0.01 m^{2}}{2 \pi(0.01 m)}-\frac{0.01 m}{2}=\frac{1.00 m-\pi(0.01 m)}{2 \pi} \\
& =0.154 m=>\therefore b=0.164 m \\
& C=h \frac{2 \pi \varepsilon_{r} \varepsilon_{0}}{\ln \left(\frac{b}{a}\right)}=0.01 \frac{2 \pi(80)\left(8.8562 \times 10^{-12}\right)}{\ln \left(\frac{0.164}{0.154}\right)} \\
& =708.26 \mathrm{pF}
\end{aligned}
$$

The reactance $\left(X_{c}\right)$ of the capacitor:

$$
\begin{gathered}
X_{c}=\frac{1}{j \omega C}=\frac{1}{j\left(80 \pi \times 10^{3}\right)\left(708.5 \times 10^{-12}\right)} \\
=-j 5.6178 \mathrm{k} \Omega
\end{gathered}
$$

\subsubsection{Cylindrical Tubes Resistance:}

The resistance of this design is given by [12]:

$$
R=\rho\left[\ln \left(\frac{b}{a}\right) / 2 \pi h\right],
$$

Where: $\rho$ : The resistance for each meter which equal in this design $\rho_{\text {distilled water }}=5 k \Omega . m, a$ : Inner radii in meter $(\mathrm{m}), b$ : Outer radii in meter $(\mathrm{m}), h$ : The height of the cylindrical in meter $(\mathrm{m}), h=0.01 \mathrm{~m}$. Therefore, the resistor of this system is:

$$
R=5 k \Omega . m[\ln (0.164 / 0.154) /(2 \pi(0.01 m))=5002 \Omega
$$

\subsubsection{Cylindrical Tubes Impedance:}

The impedance of this design is $Z_{\text {cell }}$ and since the resister is parallel to the capacitor, the impedance will be:

$$
\begin{aligned}
Z_{\text {cell }}=\frac{X_{c} R}{X_{c}+R} & =\frac{\left(-j 5.6178 \times 10^{3}\right)\left(5.002 \times 10^{3}\right)}{-j 5.6178 \times 10^{3}+5.002 \times 10^{3}} \\
& =2.79 k-j 2.48 k \Omega
\end{aligned}
$$

The magnitude of the impedance is:

$$
Z=\left|Z_{\text {cell }}\right|=|2.79 k-j 2.48 k|=3.736 k \Omega
$$

The equivalent circuit for these cylindrical tubes is like the one given in Figure 3.

\subsubsection{Cylindrical Tubes Mean Voltage:}

To calculate the mean current $i$, the mean voltage $v$ needs to be calculated. Therefore, the alternate voltage $\mathrm{V}$ can be found:

$$
\begin{gathered}
S_{\text {avr }}=\frac{V^{2} \text { avr }}{Z}=\frac{1.5 v^{2}}{Z} \Rightarrow \\
\begin{array}{c}
v=\sqrt{\frac{S_{\text {avr }} Z}{1.5}}=\sqrt{\frac{(0.25)(3.736 k)}{1.5}} \\
=24.952 \mathrm{~V}
\end{array}
\end{gathered}
$$

The mean voltage $v=29.75$,. The Alternate voltage $\mathrm{V}$ is:

$$
V=24.952\left(1+\cos \left(80 \pi t \times 10^{3}\right)\right) \boldsymbol{V}
$$

\subsubsection{The Effective Current:}

The effective current is that current will pass through the water to separate it to HHO. The alternate current is given by:

$$
\begin{aligned}
I= & \frac{V}{Z}=\frac{24.952\left(1+\cos \left(80 \pi t \times 10^{3}\right)\right)}{3.736 k \Omega} \\
= & 6.7\left(1+\cos \left(80 \pi t \times 10^{3}\right)\right) m A \\
& =>\text { Mean current } \mathrm{i}=6.7 \mathrm{~mA}
\end{aligned}
$$

\subsubsection{Released Volume of HHO:}

Similarly, to calculate the volume and energy of the released HHO gases, the current needs to be convert to moles. Since each mole of electrons passes from cathode to anode will release $\frac{1}{2} \mathrm{H}_{2}$ and $\frac{1}{4} \mathrm{O}_{2}$, Then: 
$\Rightarrow$ Convert amperes to electrons:

$$
\begin{gathered}
i=\left(6.7 \times 10^{-3} A\right) \\
=6.7 \times 10^{-3}\left(6.28 \times 10^{18} e^{-} / s\right) \\
=42.076 \times 10^{15} e^{-} / s
\end{gathered}
$$

$\Rightarrow$ Convert electrons to moles:

$$
\begin{aligned}
i & =\frac{42.076 \times 10^{15 e^{-}} / \mathrm{s}}{6.022 \times 10^{23} e^{-} / \mathrm{mol}} \\
& =69.87 \times 10^{-9} \mathrm{~mol} / \mathrm{s}
\end{aligned}
$$

1 mol of electrons $\stackrel{\text { yields }}{\longrightarrow} \frac{1}{4}\left(2 \mathrm{H}_{2}+\mathrm{O}_{2}\right)=>$

$$
\therefore i \stackrel{\text { yields }}{\longrightarrow} 17.467 \times 10^{-9} \frac{\mathrm{mol}}{\mathrm{s}}\left(2 \mathrm{H}_{2}+\mathrm{O}_{2}\right)
$$

The volume of $\mathrm{H}_{2}$ and $\mathrm{O}_{2}$ are $24.64 \mathrm{~L}$ for one mole of them, as we derived it in the chemical section.

$$
\begin{array}{r}
1 \mathrm{~mol} \text { of }\left(2 \mathrm{H}_{2}+\mathrm{O}_{2}\right)=24.64 \mathrm{~L} / \mathrm{mol} \\
i \stackrel{\text { yields }}{\longrightarrow}\left(17.467 \times 10^{-9} \frac{\mathrm{mol}}{\mathrm{s}}\left(2 \mathrm{H}_{2}+\mathrm{O}_{2}\right)\right)(24.64 \mathrm{~L} / \mathrm{mol}) \\
=429.08 \times 10^{-9} \mathrm{~L} / \mathrm{s}\left(2 \mathrm{H}_{2}+\mathrm{O}_{2}\right)
\end{array}
$$

\subsubsection{Energy of Released HHO:}

$$
\begin{gathered}
2 \mathrm{H}_{2}(\mathrm{~g})+\mathrm{O}_{2}(\mathrm{~g}) \rightarrow 2 \mathrm{H}_{2} \mathrm{O}(\mathrm{l})+572 \mathrm{~kJ}(286 \mathrm{~kJ} / \text { mole }) \\
1 \text { mole }\left(2 \mathrm{H}_{2}+\mathrm{O}_{2}\right) \rightarrow 572 \mathrm{~kJ} / \text { mole } \\
17.467 \times 10^{-9} \mathrm{~mole}_{\mathrm{s}}\left(2 \mathrm{H}_{2}+\mathrm{O}_{2}\right) \rightarrow \\
\frac{572 \mathrm{~kJ}}{\text { mole }} 17.467 \times 10^{-9} \mathrm{~mole} / \mathrm{s}=\frac{0.0115 \mathrm{~J}}{\mathrm{~s}}=9.99 \mathrm{~mW}
\end{gathered}
$$

\subsection{Design Equations of Spiral Plate Water Cell}

The spiral design can be simulated as an inductor, capacitor and resister as illustrated in Figure 5 (The equivalent circuit for this design). Assume that the area is $A=0.01 \mathrm{~m}^{2}$, the distance between plates are $w=0.01 \mathrm{~m}$, the turns of the Spiral are $N=1$, the applied power on this design also is $\mathrm{S}=0.25 \mathrm{VA}$ and the frequency will be also $f=40 \mathrm{khz}$ as before. The accuracy of this design can be increased by increasing number of stages by each turn, the suggested number of stages $S_{k}$ are 10 .

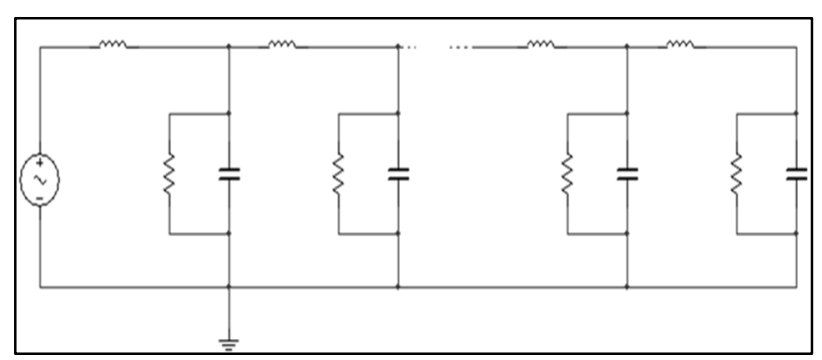

Fig.5. Spiral plates equivalent electric circuit.

\subsubsection{Spiral Plates Capacitance:}

The total capacitance of this design has two equations, the first equation can be applied when the number of turns is less or equal to one turn and the second equation can be used when the turns are more or equal to one turn as follows:

$$
\begin{gathered}
C_{N \leq 1}=\frac{2 \pi h \varepsilon}{\ln \left(\frac{(a+w) N^{2}+a+w}{(a+w) N^{2}+a}\right)} \Rightarrow 0 \leq N \leq 1, \\
C_{N \geq 1}=\frac{2 \pi h \varepsilon}{\ln \left(\frac{(a+w)(N-1)^{2}+2 a+2 w}{(a+w)(N-1)^{2}+2 a+w}\right)}+C_{N \leq 1} \Rightarrow 1 \leq N
\end{gathered}
$$

Where: C: Capacitance in Farads, $\varepsilon$ : Permittivity of dielectric (absolute, not relative), $N$ : The number of turns, $a$ : The thickness of the plate in meter (m), $a=$ $0.001 \mathrm{~m}, w$ : The distance between plates in meter (m), and $h$ : The height of the Spiral in meter (m).

\subsubsection{The Capacitor of the System:}

In order to compute the Capacitance of the system, we need firstly to calculate the height $h$ of the capacitor. The height $h$ can be found by calculate the area of spiral:

$$
2 A=0.02 m^{2}=A_{\text {spiral }}=A_{a}+A_{b}
$$

Recall the circumference equation:

$$
\begin{gathered}
R_{S}=\frac{(a+w)}{2 \pi} \theta^{2}+r \theta \rightarrow \\
A_{a}=\left.h R_{s}\right|_{r=a}=h\left(\frac{(a+w)}{2 \pi} \theta^{2}+a \theta\right)
\end{gathered}
$$

Remember that the number of turns:

$N=\frac{\theta}{2 \pi} \rightarrow A_{a}=2 \pi h\left(N^{2}(a+w)+a N\right)$

The same way for $A_{a}, A_{b}$ can be found by: 


$$
\begin{gathered}
A_{b}=\left.h R_{S}\right|_{r=a+w}=h\left(\frac{(a+w)}{2 \pi} \theta^{2}+(a+w) \theta\right) \\
=h 2 \pi(a+w)\left(N^{2}+N\right) \\
A_{\text {spiral }}=h\left(2 \pi ( N ^ { 2 } ( a + w ) + a N ) 2 \pi ( a + w ) \left(N^{2}\right.\right. \\
\quad+N))=0.02 m \\
h=\frac{0.02 m}{2 \pi(4 a+3 w)} \rightarrow h=0.09362 m
\end{gathered}
$$

The partial capacitance:

$$
\begin{gathered}
C_{S}=\frac{C}{S_{k}}=\frac{C_{N \leq 1}}{10}= \\
\frac{2 \pi \varepsilon_{0} \varepsilon_{r} h N^{2}(w(\pi+1)+a(2 \pi+1))}{10 w}=0.204 n F
\end{gathered}
$$

\subsubsection{Spiral Plates Resistance:}

The total resistance of this design has two equations, the first equation can be applied when the number of turns is less or equal to one turn and the second equation can be used when the number of turns is more or equal to one turn as follows:

$R_{N \leq 1}=\frac{\rho}{2 \pi h} \ln \left(\frac{(a+w) N^{2}+a+w}{(a+w) N^{2}+a}\right)$

$0 \leq N \leq 1$

$\frac{1}{R_{N \geq 1}}=\frac{2 \pi h}{\rho \ln \left(\frac{(a+w)(N-1)^{2}+2 a+2 w}{(a+w)(N-1)^{2}+2 a+w}\right)}+\frac{1}{R_{N \leq l}}$ if $1 \leq N$

Where: $\rho$ : The resistance for each meter which equal in this design $\rho_{\text {distilled water }}=5 k \Omega . m$., $N$ : The number of turns. $a$ : The thickness of the plate in meter (m), $a=0.001 \mathrm{~m}, w$ : The distance between plates in meter $(\mathrm{m}),=0.01 \mathrm{~m}$, and $h$ : The height of the Spiral in meter $(\mathrm{m})$. Therefore, the resistor of this system is:

$R_{S}{ }^{-1}=\frac{1}{S_{k} R}=\frac{1}{10 R_{N \leq 1}}=\frac{2 \pi h}{10 \rho \ln \left(\frac{(a+w) N^{2}+a+w}{(a+w) N^{2}+a}\right)}$

$=\frac{0.194 \mathrm{~m}^{-1}}{10}=0.019 \mathrm{~m} \Omega^{-1} \rightarrow R_{S}=51.522 \mathrm{k} \Omega$

\subsubsection{Spiral Plates Inductance:}

The total inductance of this design has two equations, the first equation can be applied when the number of turns is less or equal to one turn and the second equation can be used when the number of turns is more or equal to one turn as follows:

$L_{N \leq l}=\frac{\mu h}{2 \pi} \ln \left(\frac{(a+w) N^{2}+a+w}{(a+w) N^{2}+a}\right) \quad$ if $\quad 0 \leq N \leq 1$ $L=\frac{\mu h}{2 \pi} \ln \left(\frac{(a+w)(N-1)^{2}+2 a+2 w}{(a+w)(N-1)^{2}+2 a+w}\right)+L_{N \leq l}$ if $\quad 1 \leq N$

Where: L: Inductance in Henry, $\mu$ : Magnetic permeability (absolute, not relative), $N$ : The number of turns, $a$ : The thickness of the plate in meter (m), $a=0.001 \mathrm{~m}, w$ : The distance between plates in meter (m), and $h$ : The height of the Spiral in meter (m). Therefore, the magnetic permeability is given by [12]:

$$
\mu=\mu_{0} \mu_{r} \text {. Given that: }
$$

$\mu_{0}$ : Magnetic permeability of free space, $\mu_{0}=$ $4 \pi \times 10^{-7} \mathrm{H} \cdot \mathrm{m}^{-1}, \quad \mu_{r}$ : Relative permeability which equal in this design $\mu_{r} \approx 1$ for distilled water, partial inductor of the system:

$$
\begin{gathered}
L_{S}=\frac{L}{S_{k}}=\frac{L_{N \leq 1}}{10}= \\
\frac{2 \pi \mu_{0} w N^{2}(w(\pi+1)+a(2 \pi+1))}{10 h}= \\
\frac{11.349 n F}{10}=1.135 n H
\end{gathered}
$$

\subsubsection{Spiral Plates Impedance:}

To simplify the matter, the impedance of this design can be found in easiest way using MULTISIM as in fig. 6:

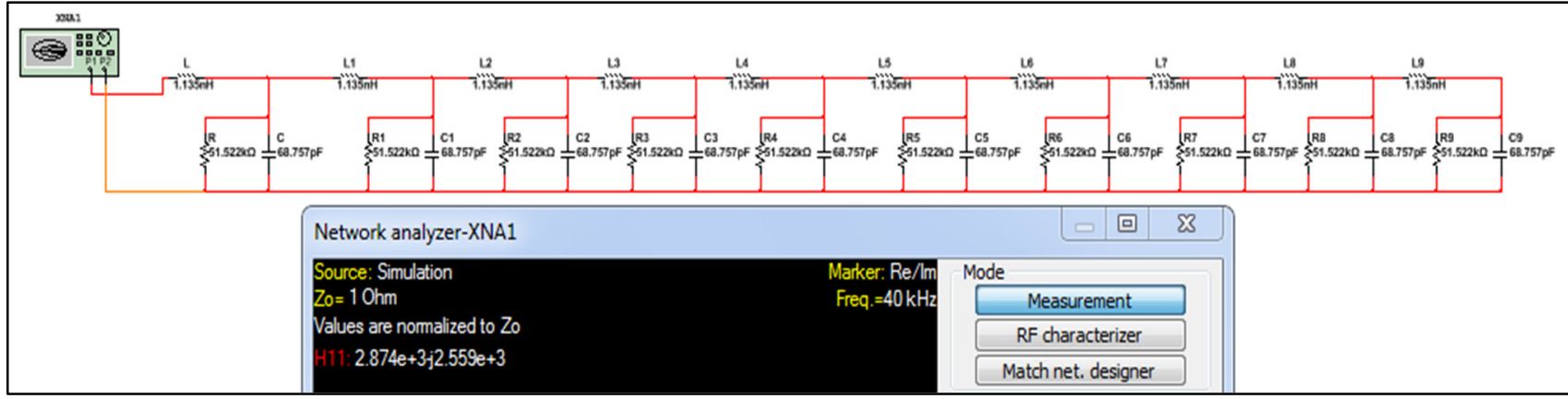

Fig. 6. Impedance measurement of spiral water cell using MULTISIM. 


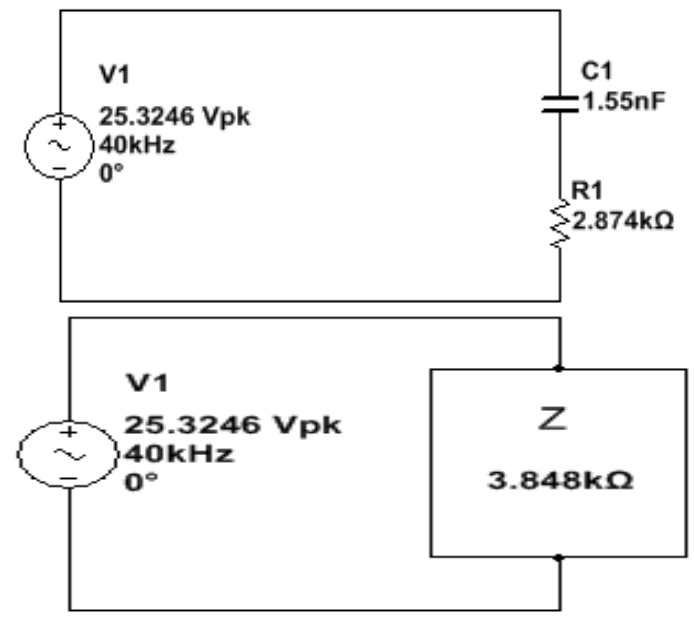

Fig. 7. Spiral plates equivalent electric circuit \& impedance.

The impedance of this system is: $Z_{\text {cell }}=2.874 k-$ $j 2.558 \mathrm{k} \Omega$. The magnitude of the impedance is: $Z=$ $\left|Z_{\text {cell }}\right|=|2.874 k-j 2.558 k \Omega|=3.848 k \Omega$. The equivalent electric circuit for Spiral plates is depicted in fig.7.

\subsubsection{Spiral Plate Mean Voltage:}

In order to calculate the mean current $i$, the mean voltage $v$ need to be calculated. Therefore, the alternate voltage $\mathrm{V}$ can be found by:

$$
\begin{gathered}
S_{a v r}=\frac{V_{a v r}^{2}}{Z}=\frac{v^{2} 1.5}{Z} \Rightarrow \\
v=\sqrt{\frac{S_{a v r} Z}{1.5}}=\sqrt{\frac{(0.25)(3.848 k)}{1.5}}=25.325 \mathrm{~V}
\end{gathered}
$$

The mean voltage $v=25.325 \mathrm{~V}$. The alternate voltage $\mathrm{V}$ is:

$$
V=25.325\left(1+\cos \left(80 \pi t \times 10^{3}\right)\right) \boldsymbol{V}
$$

\subsubsection{The Effective Current:}

The effective current is that current will pass through the water to separate it to HHO. The alternate current is given by:

$$
\begin{aligned}
I= & \frac{V}{Z}=\frac{25.325\left(1+\cos \left(80 \pi t \times 10^{3}\right)\right)}{3.848 k \Omega} \\
= & 6.6\left(1+\cos \left(80 \pi t \times 10^{3}\right)\right) m A \\
& \rightarrow \text { Mean Current: } i=6.6 \mathrm{~mA}
\end{aligned}
$$

The equivalent circuit of parallel spiral cell along with its simulation results of using Multisim is given in figure 8 .

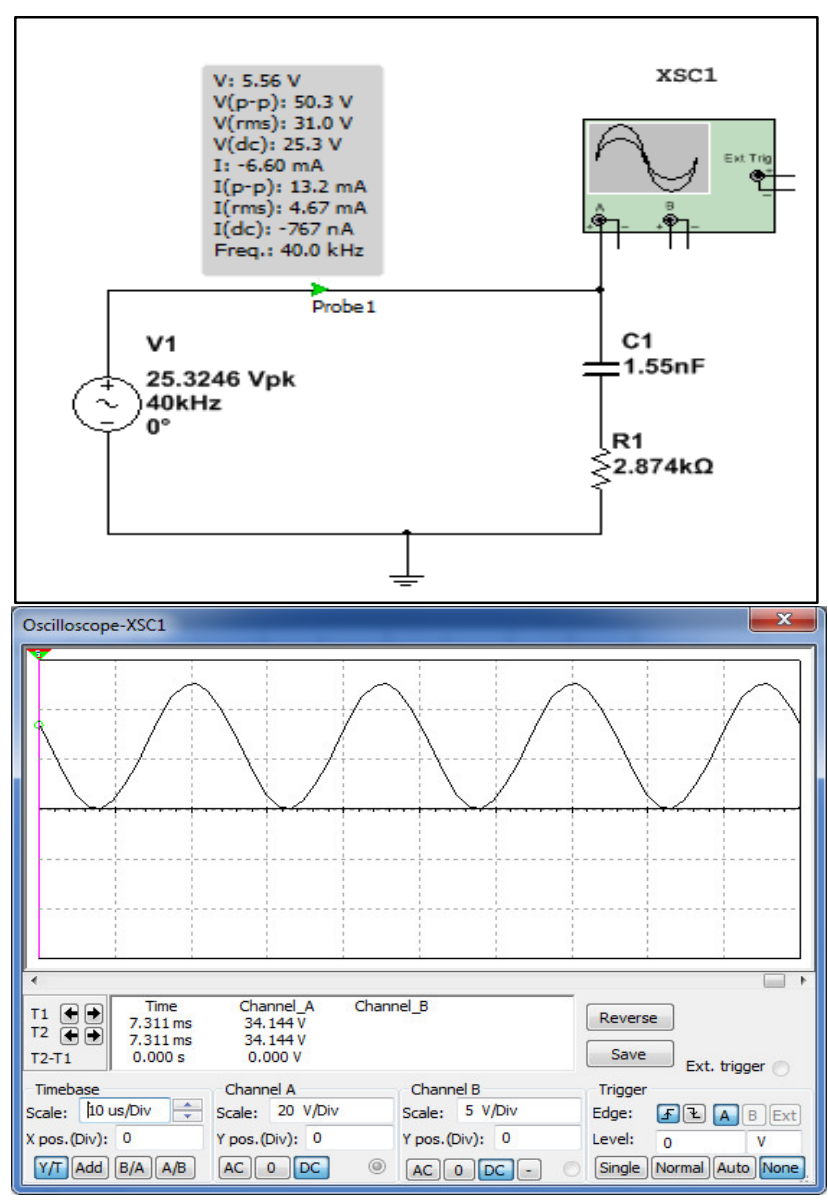

Figure 8: (a) Equivalent circuit of sprial plate, (b)Simulation result of Spiral plate using MULTISIM.

\subsubsection{Released Volume of HHO:}

In order to calculate the volume and energy of released HHO gases, the current needs to be convert to moles. Since, it is known that Each mole of electrons passes from cathode to anode will release $\frac{1}{2} \mathrm{H}_{2}$ and $\frac{1}{4} \mathrm{O}_{2}$.

$\Rightarrow$ Convert amperes to electrons:

$$
i=\left(6.6 \times 10^{-3} A\right)=41.45 \times 10^{15} e^{-} / s
$$

$\Rightarrow$ Convert electrons to moles:

$$
\begin{gathered}
i=\frac{41.45 \times 10^{15 e^{-} / \mathrm{s}}}{6.022 \times 10^{23 e^{-}} / \mathrm{mol}}=68.8 \times 10^{-9} \mathrm{~mol} / \mathrm{s} \\
1 \mathrm{~mol} \text { of electrons } \stackrel{\text { yields }}{\longrightarrow} \frac{1}{4}\left(2 \mathrm{H}_{2}+\mathrm{O}_{2}\right) \rightarrow \\
i \stackrel{\text { yields }}{\longrightarrow} 17.2 \times 10^{-9} \frac{\mathrm{mol}}{\mathrm{s}}\left(2 \mathrm{H}_{2}+\mathrm{O}_{2}\right)
\end{gathered}
$$

The volume of $\mathrm{H}_{2}$ and $\mathrm{O}_{2}$ is $24.64 \mathrm{~L}$ for one mole of them, as derived it in the chemical section. 


$$
\begin{gathered}
1 \text { mol of }\left(2 \mathrm{H}_{2}+\mathrm{O}_{2}\right)=24.64 \mathrm{~L} / \mathrm{mol} \\
i \stackrel{\text { yields }}{\longrightarrow}\left(17.2 \times 10^{-9} \frac{\mathrm{mol}}{\mathrm{s}}\left(2 \mathrm{H}_{2}+\mathrm{O}_{2}\right)\right)(24.64 \mathrm{~L} / \mathrm{mol}) \\
=424 \times 10^{-6} \mathrm{~L} / \mathrm{s}\left(2 \mathrm{H}_{2}+\mathrm{O}_{2}\right)
\end{gathered}
$$

\subsubsection{Energy of Released HHO:}

$$
\begin{gathered}
2 \mathrm{H}_{2}(\mathrm{~g})+\mathrm{O}_{2}(\mathrm{~g}) \rightarrow 2 \mathrm{H}_{2} \mathrm{O}(\mathrm{l})+572 \mathrm{~kJ}(286 \mathrm{~kJ} / \mathrm{mole}) \\
1 \text { mole }\left(2 \mathrm{H}_{2}+\mathrm{O}_{2}\right) \rightarrow 572 \mathrm{~kJ} / \text { mole } \\
P=17.2 \times 10^{-9} \text { mole } / \mathrm{s}\left(2 \mathrm{H}_{2}+\mathrm{O}_{2}\right) \\
\rightarrow \frac{572 \mathrm{~kJ}}{\text { mole }} 29.5 \times 10^{-9} \text { mole } / \mathrm{s}=9.8 \mathrm{~mW}
\end{gathered}
$$

\section{Obtaining Maximum Efficiency}

In order to get the maximum efficiency of the system, the system parameters have to be defined with threshold values in which each single parameter is selected with minimum enhanced value that can contribute efficiently to the overall system. In the meantime, the input voltage should not be less than $1.23 \mathrm{~V}$, otherwise the water electrolysis will produce nothing [13]. Also, the amount of HHO released depend on the amount of the current, on the other hand the increase of amount of current will increase the heat. To avoid the increasing of heat with maximum amount of current, the current should be alternated. Moreover, by increasing the area, the temperature and the resistance will decrease while changing the frequency value will change the impedance of the water. Finally, balancing all these parameters should give a maximum efficiency as follows:

$\Rightarrow$ Voltage:

$$
\begin{gathered}
V=1.23(1+\cos (\omega t)) V, \\
S=0.25 V A, \quad i=203 m A
\end{gathered}
$$

$\Rightarrow$ Impedance:

$$
\begin{gathered}
Z=\left|Z_{\text {cell }}\right|=\left|\frac{R \cdot j X_{c}}{R+j X_{C}}\right| \\
=|R(-j 1 / 2 \pi f C) /(R-j(1 / 2 \pi f C))|=6.06 \Omega
\end{gathered}
$$

$\Rightarrow$ Frequency:

$$
f=\sqrt{ }\left(R^{\wedge} 2-36.724\right) / 12.12 \pi C R \text { for } R \text { and } C
$$

\subsection{The Temperature of Water Cell}

The equation that describe the change in temperature due to current density is given by [14]:

$$
\Delta T=\frac{I^{2} R}{V_{\text {volume }} \rho c} d t=\frac{P}{V_{\text {volume }} \rho c} d t
$$

Where: $\Delta \boldsymbol{T}$ : Temperature difference in kelvin, $\boldsymbol{V}_{\text {volume }}$ : The volume that current pass through, $\boldsymbol{\rho}$ : Mass density of water, $\rho=\mathbf{1} \mathbf{g} /\left(\mathbf{c m}^{\wedge} \mathbf{3}\right)=\mathbf{1} \times$ $\left(10^{6}\right) g / m^{\wedge} 3, \quad c$ : Heat capacity of water, $c=$ $4.18 \mathrm{~J} /(\boldsymbol{g} \cdot \boldsymbol{K})$. To obtain the maximum efficiency, the temperature must be constant over time as much as possible. Which mean we will try to make this equation almost zero. This is clearly illustrated in Fig. 9.

$$
\begin{aligned}
& R=Z=6.06 \Omega, I=i=0.203 A \rightarrow \\
& \Delta T=\frac{(0.203)^{2} 6.06}{V_{\text {volume }}\left(1 \times 10^{6}\right)(4.18)} d t=\frac{59.7 n}{V_{\text {volume }}} \boldsymbol{K} \cdot \boldsymbol{s}
\end{aligned}
$$

The temperature of the water cell can be given by:

$$
\int \Delta T d t=\int \frac{P}{V_{\text {volume }} c \rho} d t \rightarrow T(t)=\frac{P}{V_{\text {volume }} \rho c}+T_{0}
$$

Where: $T(t)$ : The temperature as function of time and $\mathrm{T}_{0}$ : The initial temperature.

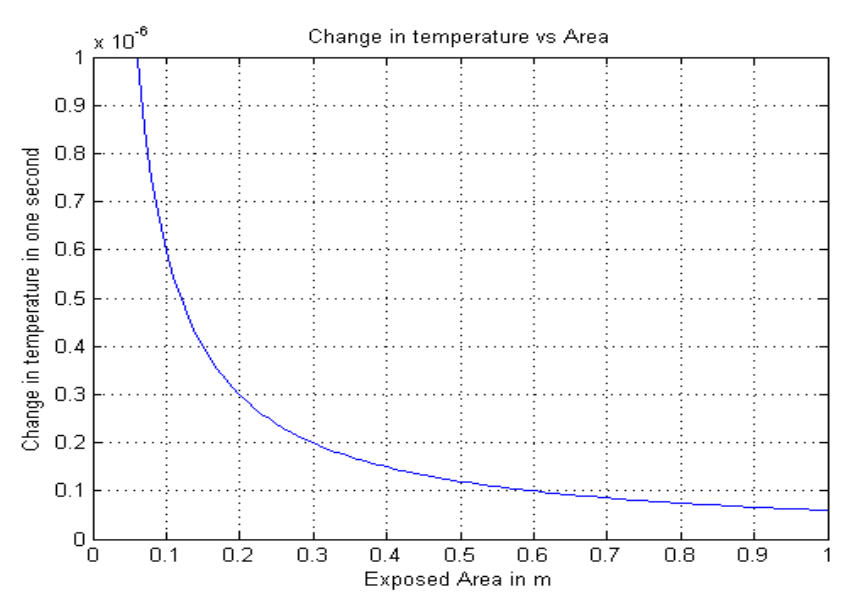

Figure 9: The change in temperature verses area.

\subsection{Shaping the input Signal}

The shape of the signal plays a significant role in obtaining the maximum efficiency. As alluded before, the voltage used to separate the water should never be less than $1.23 \mathrm{~V}$, this is to avoid any loss in the power. The original pre-processed signal is the sinusoidal signal which don't provide the maximum efficiency in electrolysis operation since it makes some losses due to the curvy rise and fall. Therefore, the best signal to be applied here is the periodic signal with fast rising and falling and has a controlled duty cycle. Thus, we have selected the Pulse Width Modulation (PWM) signal which is obtained by multiplying the amplitude by sinusoidal as shown in fig. 10. The function of PWM signal in time domain, can be given by: 
$\mathrm{V}_{\mathrm{pwm}}(t)=\frac{B}{2}\left(1+\frac{\cos \left(\omega \frac{k}{2} t-\frac{\pi}{2}(2 \tau-1)\right) \sin \left(\omega \frac{k}{2} t\right)}{\left|\cos \left(\omega \frac{k}{2} t-\frac{\pi}{2}(2 \tau-1)\right) \sin \left(\omega \frac{k}{2} t\right)\right|}\right)$

Where: $\tau$ : The pulse width ratio, $\tau=T_{o} / T_{p}, B$ : The amplitude, $k$ : No. of period inside one sinusoidal period, $k=T_{s} / T_{p}$. The average of PWM signal can be given: $V_{p w m}=\frac{1}{T} \int_{0}^{T_{p}} V_{p w m}(t) d t=1.23, \frac{B}{2}(1+(2 \tau-1))=1.23, B=\frac{1.23}{\tau}$

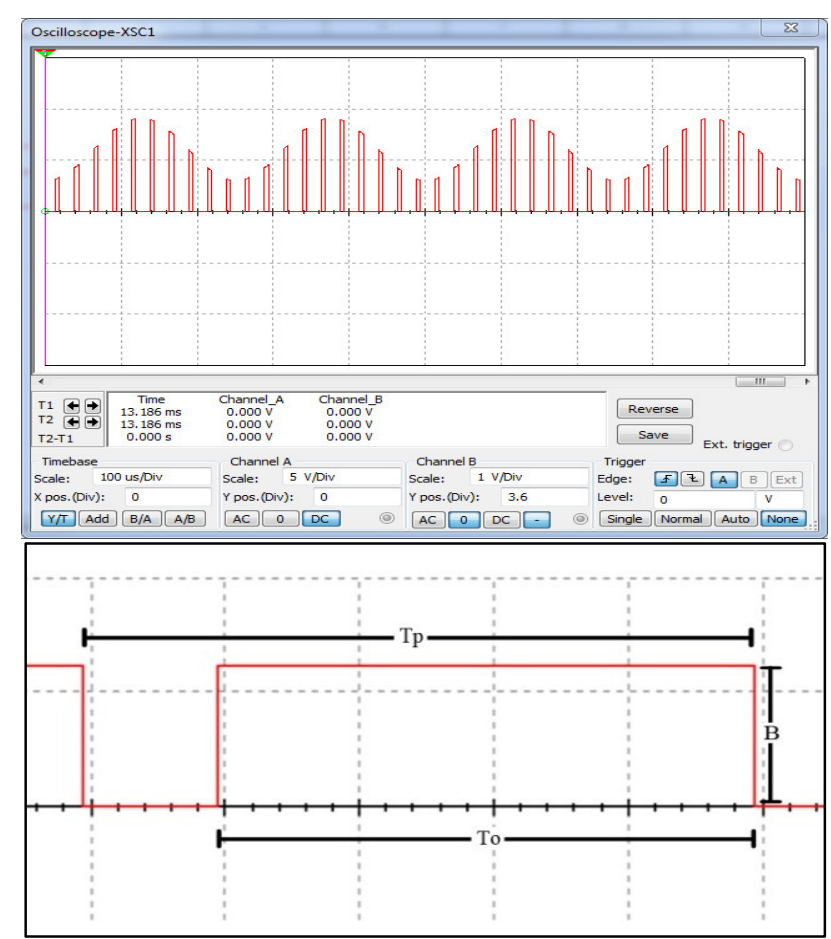

Figure 10: (a) Signal for electrolysis (b) PWM signal

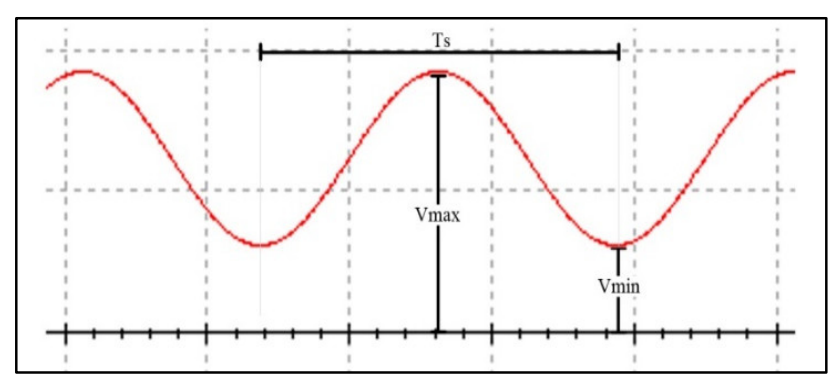

Figure 11: Sinusoidal signal

The function of sinusoidal signal (shown in fig.11) in time domain can be given by:

$$
V_{1}(t)=\frac{V_{\max }}{2}(\cos (\omega t)+1)+V_{\min }
$$

Where the average of sinusoidal signal is equal to the amplitude of PWM signal:

$B=\frac{V_{\max }+V_{\min }}{2} ; V_{\min }=1.23 \mathrm{~V}$ where Sinusoidal

Amplitude is $V_{\max }=1.23\left(\frac{2}{\tau}-1\right)$

The result of multiply sinusoidal signal by the normalized PWM signal is: $V(t)=\frac{1}{B} V_{p w m}(t) V_{1}(t)$

$$
\begin{aligned}
V(t)= & \frac{1}{2}\left(1+\frac{\cos \left(\omega \frac{k}{2} t-\frac{\pi}{2}(2 \tau-1)\right) \sin \left(\omega \frac{k}{2} t\right)}{\left|\cos \left(\omega \frac{k}{2} t-\frac{\pi}{2}(2 \tau-1) \sin \left(\omega \frac{k}{2} t\right)\right)\right|}\right) \\
& *\left(1.23\left(\frac{1}{\tau}-\frac{1}{2}\right)(\cos (\omega t)+1)+1.23\right)
\end{aligned}
$$

The signal simulation at various stages of processing is illustrated in figure 12 .

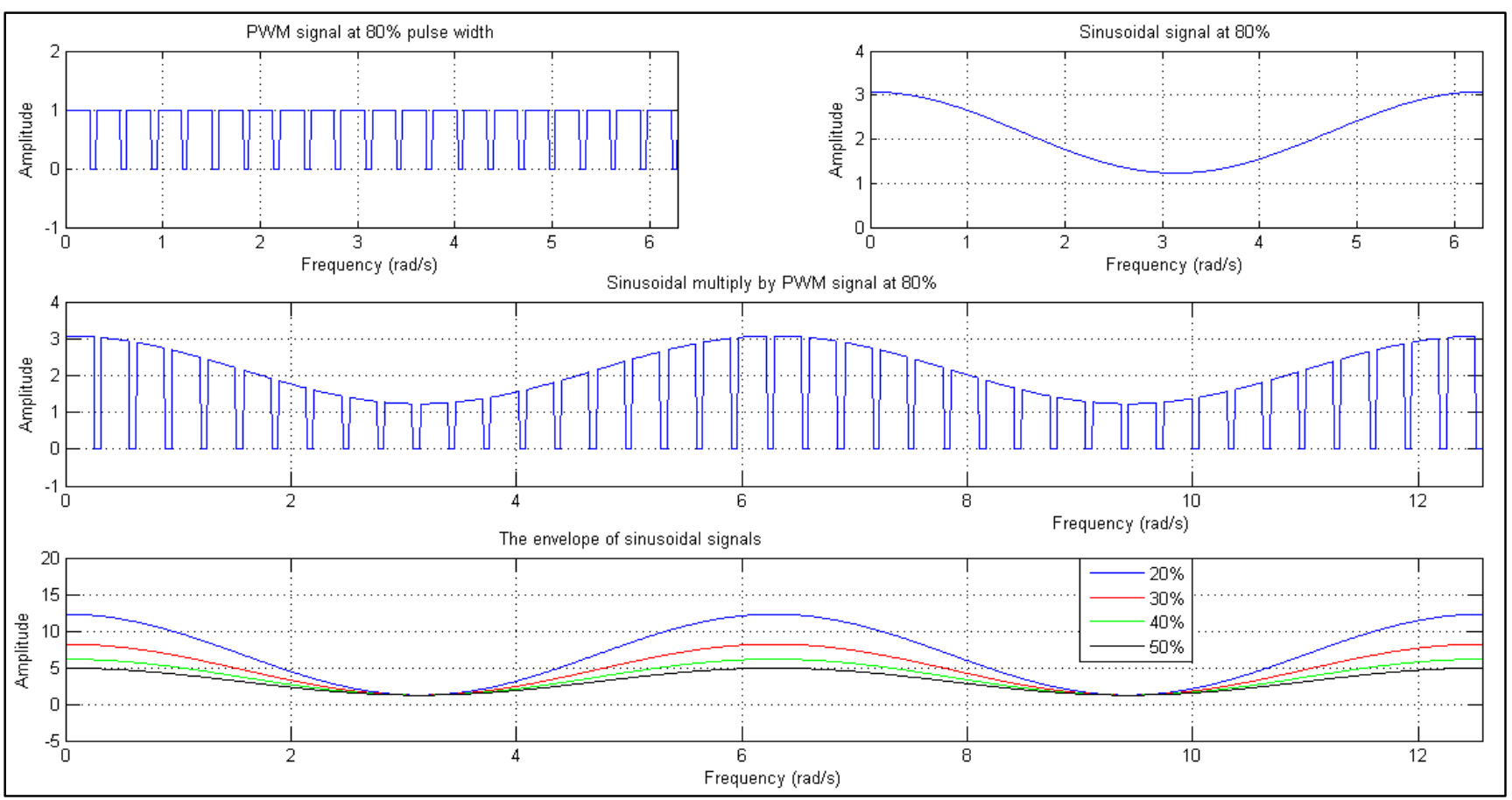

Figure 12: The signal simulation at different stages of processing. 


\section{Comparisons and Analysis}

To evaluate the proposed models, several parameters of the system can be tuned and processed such as power consumption, operational frequency, and released gas volume. Thus, we have extensively measured and analyzed two significant relations: power versus volume and frequency versus volume. For instance, figure 13 shows the relationship between the injected power and the volume of released HHO gas for the three proposed models. It can be clearly noticed that increasing the injected power will exponentially increase the released amount of. The difference in the behavior between the three models can be related to the impedance of the systems. Therefore, the efficiency will be increased when the injected power decreased. Also, the released amount of HHO almost the same for the three designs when the applied power increased at frequency $40 \mathrm{KHz}$.

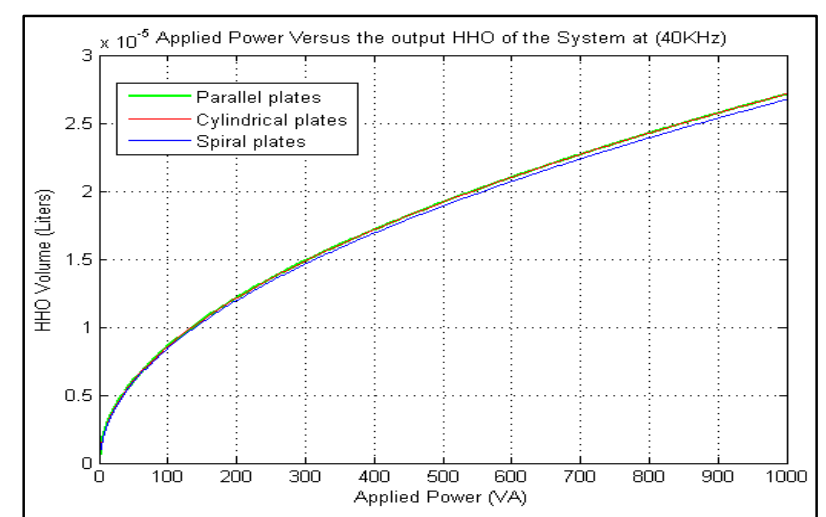

Figure 13: The applied power versus output amount of $\mathrm{HHO}$ at $40 \mathrm{KHz}$ for the three different designs.

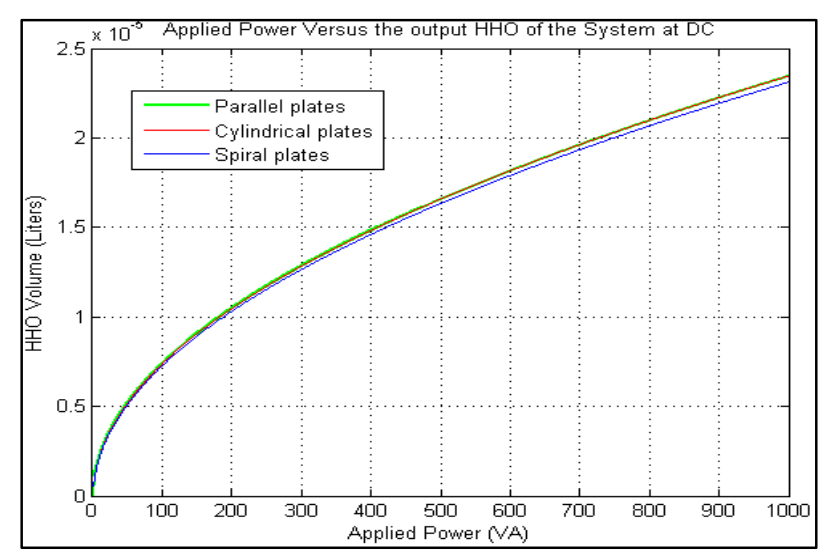

Figure 14: The applied power versus output amount of $\mathrm{HHO}$ at $\mathrm{DC}$ for the three different designs.

Similar tendency has been noticed when we tune the power at the DC Signal as shown in figure 14 since the released amount of $\mathrm{HHO}$ is almost equivalent for the three models when the applied power increased at DC signal. Also, the released amount of HHO is very high for spiral plate compared to the other designs, since the frequency that have been used is $85.45 \mathrm{MHz}$ as clearly illustrated in figure 15. The applied power influences the impedance of the system, since it increases the temperature of the system according to previous equations, which will decrease the impedance of the system.

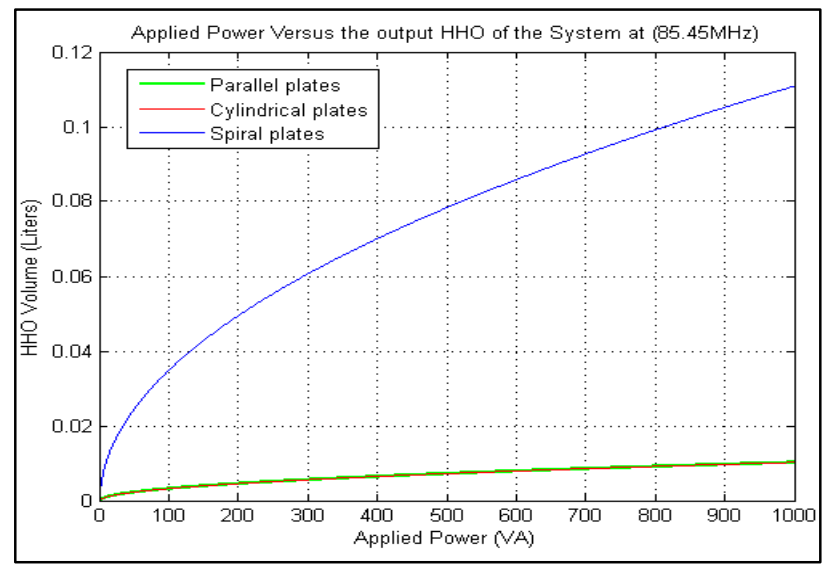

Figure 15: The applied power versus output amount of $\mathrm{HHO}$ at $85.45 \mathrm{MHz}$ for the three designs.

Regarding the relationship of frequency versus volume: the frequency is a significant factor for the electrolysis process since it mainly affects the system that has imaginary impedance. Also, changing frequency can be used to reduce the temperature. In figure 16, we can see the effect of changing the frequency on the volume of released HHO gas. The parallel and cylindrical plates are linearly affected since both models have similar resistance and capacitance while the spiral plates have a different characteristic, since it consists of three elements resistance, capacitance and inductance.

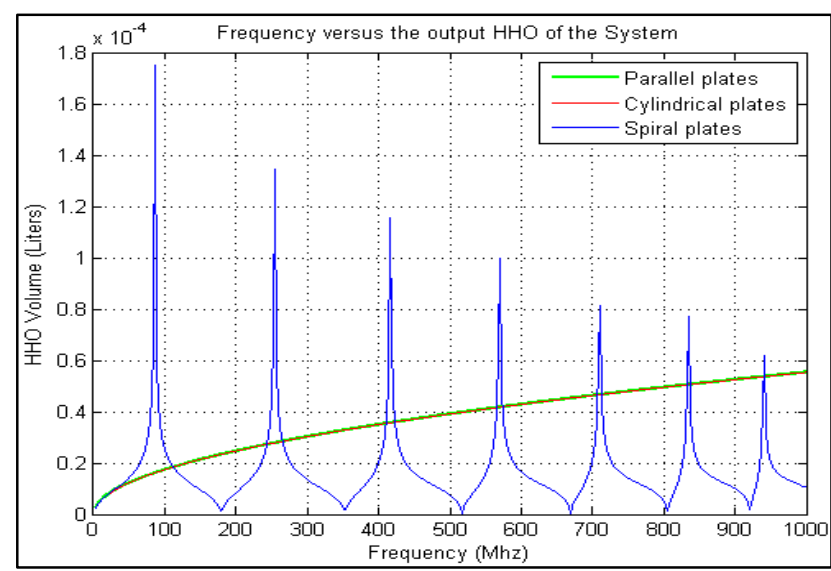

Figure 16: Frequency Vs output amount of HHO for the three distinctive designs.

Finally, figure 17 shows the conductivity of spiral plates system, which prove that the main effect in this 
situation resulted from having of both capacitance and inductance in the same system.

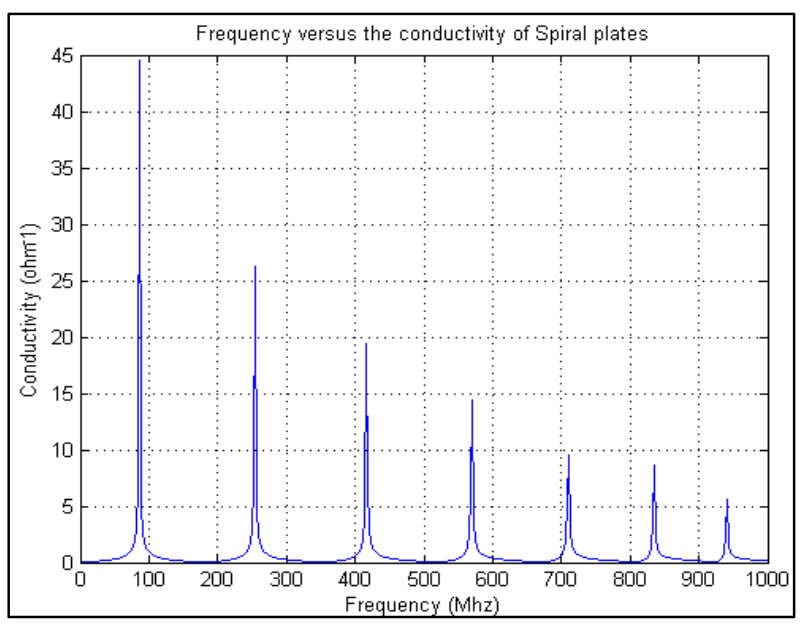

Figure 17: Frequency Vs conductivity of spiral plate.

\section{Practical Applications}

HHO energy generator and storage have been widely used in many real-life applications especially those related to vehicle automation technologies as in [1518]. Authors of [15] proposed an approach to increase fuel efficiency in spark ignition engines. They designed an efficient HHO generator that produces Hydroxy gas which can be used to increase the fuel efficiency in an internal combustion engine. Their study mainly focused on finding an efficient configuration of an ordinary $\mathrm{HHO}$ generator that is efficient than an ordinary system. As a result, they concluded that the amount of unburned fuel in a combustion engine was reduced. Here the generator was tested under several conditions in order to determine a convenient design for an efficient $\mathrm{HHO}$ generator and therefore, such a system will be able to increase the power of a spark ignition engine while reducing the air pollution.

Also, researchers of [16] presented an application of dry cell HHO gas generator with pulse width modulation (PWM) with variable duty cycle on SINJAI spark ignition engine performance. They applied the HHO gas generated subsequently to the SINJAI spark ignition engine port injection, 2cylinder $650 \mathrm{cc}$ with gas inlet mechanism using a venturi. Variations performed on $\mathrm{HHO}$ gas generator is the duty cycle of pwm, i.e. $20 \%, 40 \%, 60 \%, 80 \%$ and $100 \%$ (or the same as non pwm). Their results showed that the optimum performance of $\mathrm{HHO}$ gas generator is generated by pwm system with $40 \%$ duty cycle with parameters such as specific energy input of $33,121 \mathrm{MJ} / \mathrm{kg}$, generator efficiency of $20,064 \%$ and generator temperature can be maintained below 60 0C. Also, the application of HHO gas generator increased many engine performances factors such as torque, power, BMEP and thermal efficiency respectively of $2.27 \%, 2.76 \%$ and $3.05 \%$ and a decrease of BSFC $7.76 \%$.

Moreover, the study in [17] provided an overview of classification of the vehicles using hydrogen with two main categories as designs in which hydrogen is burned and energy is generated by conversion to electricity. Thus, they showed that the designs of internal combustion vehicles with using hydrogen via burning, the designs of the fuel cell vehicles that using hydrogen by converting into electricity and their hybrid versions have been introduced. In the automotive industry, the structure and future advantages of hydrogen fuel cell electric vehicles have been handled in a separate title. Onboard storage, safety, the capital cost and operating cost of the different design of vehicles have been analyzed rigorously. Finally, the contributor of [18] examined the effect of HHO gas that was directly injected into a single cylinder diesel engine, on the manifold intake air at varying operating speeds of 1,500-3,000 rpm in diesel engine. Their experiments demonstrated positive results including (13.87-15.48\%) fuel consumption reduction, lower exhaust temperature, and consequently a reduction in pollution. Furthermore, results indicated that the injection of $\mathrm{HHO}$ improved the combustion efficiency and increased the brake thermal efficiency by an average of approximately $17.1 \%$.

Unlike aforementioned works, in this paper we are providing three different mathematical models and simulations of the HHO generation cell where the designs were modeled into three electric circuits to calculate the plate's parameters such as resistance, inductance and capacitance.

\section{Conclusions}

In this paper, three designs have been proposed for the internal plates as illustrated previously. Each design has been modeled into electric circuit to calculate the plates parameters such as resistance, inductance and capacitance. Based on these three parameters, a theoretical comparison has applied to determine the optimum design. As a result, the spiral plate shows the best figures in terms of high amount of hydrogen and oxygen gases emission. Moreover, in terms of maximum efficiency, increasing the efficiency depends on minimizing the voltage at least to be $1.23 \mathrm{~V}$ which will increase the effective current. Finally, shaping the signal, which is related to the voltage and temperature, will lead to stabilizing the temperature and prevent the power from converting into heat. 
References:

[1]. S. A. Musmar, A. A. Al-Rousan, "Effect of HHO gas on combustion emissions in gasoline engines", Fuel, Elsevier, Vol. 90, No10, 2011, Pages 3066-3070.

[2]. K.C. Divya, Jacob Østergaard, "Battery energy storage technology for power systems-An overview", Electric Power Systems Research, Elsevier, Vol. 79, No. 4, 2009, Pps 511-520.

[3]. Maik Streblau, Mihail, Simov, Bohos Aprahamian, Tatyana Dimova "The influence of the electrolyte parameters on the efficiency of the oxyhydrogen (HHO) generator", IEEE Electrical Apparatus and Technologies (SIELA), 2014.

[4]. R. A Erren and W. H. Campbell, "Hydrogen: A Commercial Fuel for Internal Combustion Engines and Other Purposes", Journal of the Institute of Fuel, Vol. 6, Pages 277-90, 1993.

[5]. A. Yilmaz, E. Uludamar, K. Ayfin, Effect of hydroxy $(\mathrm{HHO})$ gas addition on performance and exhaust emissions in compression ignition engines, International journal of hydrogen energy, vol. 35, 2010, pp. 11366-11372

[6]. A. Al-Rousan, "Reduction of fuel consumption in gasoline engines by introducing $\mathrm{HHO}$ gas into intake manifold", International Journal of Hydrogen Energy, vol 35, 2010, pp.1293012935.

[7]. R. F. Stebar and F. B Parks, "Emission Control with Lean Operation Using HydrogenSupplemented Fuel. SAE Paper (Document No.740192), 1974

[8]. R. M. Zweig, "Proceedings of the Ninth World Hydrogen Energy Conference", Oct 1992, Paris, France.
[9]. Ed. K. Lee Lerner and Brenda Wilmoth Lerner," The Gale Encyclopedia of Science". 4th ed. Vol.1. Detroit: Gale, 2008.

[10]. United States Patent, Patent number 4,936,961, Jun, 26,1990.

[11].Power Generation Technologies, Second Edition, 2014, Pages 129-152

[12].Fuel Cell Today Organization, Water Electrolysis \& Renewable Energy System.

[13]. Raza, Maimuna, Environment pollution, Pakistan Observer [Islamabad] 17 Sep 2012.

[14]. Union of Concerned Scientists, (ucsusa.org), DateDec.22,2014.

[15].TS De Silva, L Senevirathne and TD Warnasooriya, "HHO Generator - An Approach to Increase Fuel Efficiency in Spark Ignition Engines", European Journal of Advances in Engineering and Technology, 2015, 2(4): 1-7.

[16]. B. Sudarmanta, S. Darsopuspito, D. Sungkono, "application of dry cell HHO gas generator with pulse width modulation on SINJAI spark ignition engine performance", IJRET: International Journal of Research in Engineering and Technology, Volume: 05, Issue: 02, Feb-2016.

[17].M. Gurz, et. al., "The meeting of hydrogen and automotive: A review", International Journal of Hydrogen Energy, Elsevier, Volume 42, Issue 36, 7, 2017, Pages 23334-23346.

[18].A. A. Al-Rousan, "Green transportation: increasing fuel consumption efficiency through HHO gas injection in diesel vehicles", International Journal of Global Warming, Inderscience, Volume 14, Issue, 3, 2018. 